\title{
Study on Review Criteria of BIM Design Model for Prefabricated Concrete Project
}

\author{
Ning $\mathrm{XU}^{1,2, a}$, Guangbin Wang ${ }^{1, b}$ \\ ${ }^{1}$ School of Economics and Management, Tongji University, Shanghai, China \\ ${ }^{2}$ Shanghai Ershiye Construction Co., Ltd., Shanghai, China \\ a123xn@tongji.edu.cn, bob_wang@tongji.edu.cn
}

\begin{abstract}
Keywords: review criteria, BIM, design model, prefabricated concrete
Abstract. Based on the comparative analysis of model between PC (prefabricated concrete) structure and traditional cast-in-place structure, a review process of BIM design model for PC project was established. Moreover, a review criteria of BIM design model for PC project was proposed, which includes the division of design interface, the model precision and so on. Taking a real PC project as an example, many review points of BIM design model for PC project were demonstrated vividly. It was shown that the review criteria of BIM model for PC project can solve the problem of information transfer effectively.
\end{abstract}

\section{Introduction}

Before the application of BIM technology at the construction stage for the general contractor, an important step is to review the BIM design model which created by the designer during the design stage [1]. At present, there are no uniform codes and standards for the review criteria of BIM models at home and abroad. The existing related standards mainly focus on the inspecting of model quality [2], such as the appearance inspection of dimensional deviations, model collision detection, which are not suitable for the actual needs of BIM application for construction companies.

In addition, compared with the traditional construction, PC structures have developed rapidly in recent years due to their production in the factory, on-site installation, less construction period, less on-site wet operations, better environmental protection and less material waste [3]. Because of the differences of BIM design model between the PC structure and the traditional structure, the review of the model for PC structure needs further study.

This paper will propose a new review process and review criteria of BIM design model for PC project, based on the comparative analysis of the model between PC structure and traditional cast-in-place structure. With the real example of PC project in Shanghai, the review criteria will be demonstrated clearly, and it will provide a reference for the implementation of post similar projects.

\section{Model Differences between PC and Traditional Cast-in-place Structure}

Based on the characteristics of PC structure, considering the establishing principle of BIM model, the model differences between PC structure and traditional cast-in-place structure are analyzed as Table.1. As can be seen from the Table.1, there are many model differences between PC and traditional cast-in-place structure. When reviewing the BIM design model, more attention should be paid to the differences.

\section{Review Process of BIM Design Model for PC Project}

In order to review the BIM design model of PC project quickly, efficiently, and accurately, a standard process for model review is established as Fig.1. 
Table.1 Model differences between PC and traditional cast-in-place structure

\begin{tabular}{|c|c|c|}
\hline $\begin{array}{l}\text { Model } \\
\text { Differences }\end{array}$ & $\begin{array}{c}\text { PC Structure } \\
\text { ( Prefabricated integrated shear wall residence ) }\end{array}$ & $\begin{array}{l}\text { Traditional Cast-in-place } \\
\text { Structure } \\
\text { ( Shear wall residence ) }\end{array}$ \\
\hline $\begin{array}{l}\text { Cast-in-plac- } \\
\text { e parts }\end{array}$ & Basement and floor 1 to 2 structure & All floors are fully casted \\
\hline $\begin{array}{l}\text { Prefabricate- } \\
\text { d parts }\end{array}$ & $\begin{array}{l}\text { Many kinds of prefabricated parts, and component } \\
\text { models. Small cast-in-place model }\end{array}$ & Full cast, No precast model \\
\hline Floor model & $\begin{array}{l}\text { Many standard apartment types which can be } \\
\text { assembled }\end{array}$ & $\begin{array}{l}\text { No standard apartment type, } \\
\text { not assemble }\end{array}$ \\
\hline $\begin{array}{l}\text { Apartment } \\
\text { model }\end{array}$ & $\begin{array}{l}\text { Including horizontal and vertical prefabricated } \\
\text { components. Horizontal prefabricated components } \\
\text { include prefabricated composite slab, balcony slab, } \\
\text { etc. Vertical prefabricated components include } \\
\text { shear walls, etc. }\end{array}$ & $\begin{array}{l}\text { No horizontal prefabricated } \\
\text { components and vertical } \\
\text { prefabricated components. }\end{array}$ \\
\hline Joint & $\begin{array}{l}\text { Joint model between horizontal and vertical } \\
\text { prefabricated components, such as sealant, slurry, } \\
\text { PE bar }\end{array}$ & $\begin{array}{l}\text { Joint model between } \\
\text { horizontal and vertical } \\
\text { prefabricated components }\end{array}$ \\
\hline $\begin{array}{l}\text { Component } \\
\text { model }\end{array}$ & $\begin{array}{l}\text { Including embedded parts for supporting and lifting } \\
\text { of prefabricated components, and reserved hole, } \\
\text { etc. }\end{array}$ & $\begin{array}{l}\text { No embedded parts model } \\
\text {, including the plaster } \\
\text { surface layer ,etc. }\end{array}$ \\
\hline $\begin{array}{l}\text { Electromech } \\
\text { anical model }\end{array}$ & $\begin{array}{l}\text { Existing segmented model to meet the coordinated } \\
\text { installation on site }\end{array}$ & $\begin{array}{l}\text { No segmented model, direct } \\
\text { installation on site }\end{array}$ \\
\hline Site model & $\begin{array}{l}\text { Heavy vehicle road, turning radii suitable for } \\
\text { transport of prefabricated components }\end{array}$ & $\begin{array}{l}\text { General vehicle road, } \\
\text { turning radii suitable for } \\
\text { pump truck, rebar truck, etc. }\end{array}$ \\
\hline $\begin{array}{l}\text { Temporary } \\
\text { facility model }\end{array}$ & $\begin{array}{l}\text { Heavy tower crane model, external protection } \\
\text { frame model }\end{array}$ & $\begin{array}{l}\text { General tower crane } \\
\text { Scaffold model }\end{array}$ \\
\hline $\begin{array}{l}\text { Information } \\
\text { attribute }\end{array}$ & $\begin{array}{l}\text { Not only including the information of concrete and } \\
\text { rebar, but also including the information of } \\
\text { component production, processing, hoisting, etc. }\end{array}$ & $\begin{array}{l}\text { Mainly including the } \\
\text { information of concrete and } \\
\text { rebar }\end{array}$ \\
\hline
\end{tabular}

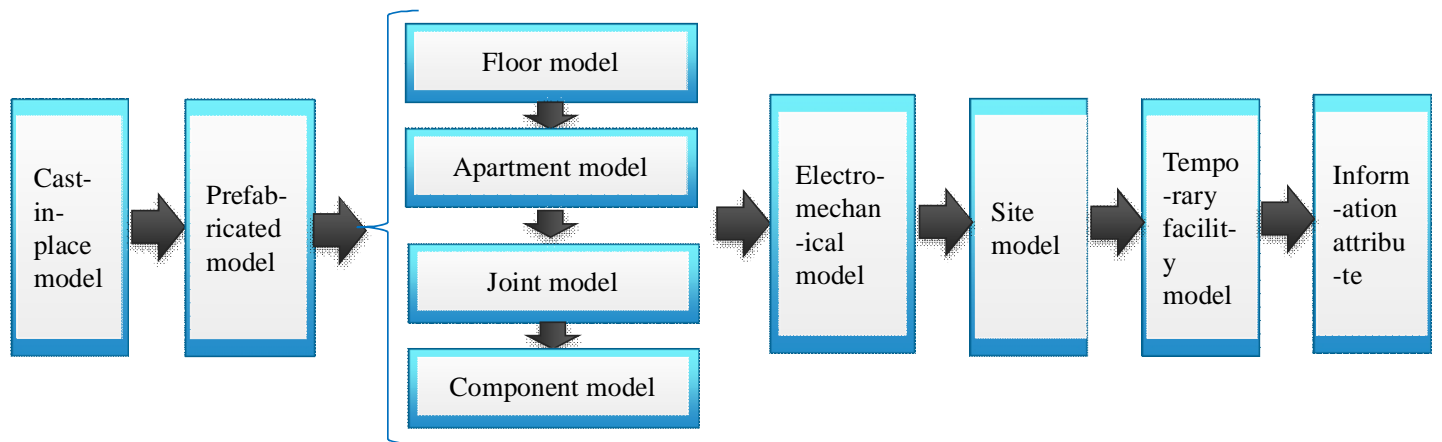

Fig.1 Review process of BIM design model for PC project 
The specific review content of each model in each stage can be referenced in Table 1. Using the process, the general contractor can review the model's mistakes, omissions, and shortages. It can also improve the applicability and utilization of the model.

\section{Review Criteria of BIM Design Model for PC Project}

Division of design interface. Before the review of design model, it is necessary to determine whether the scopes and boundaries of the BIM model submitted by the designing institute are appropriate according to the contract.

The BIM model submitted by the designing institute generally include the architecture model, structure model, electromechanical model, construction site model, integrated optimized model, reinforcement optimized model after collision, and design change model.

The main tasks on the BIM model at the stage of construction generally include creating the temporary model (such as tower cranes and scaffold model), construction site model, construction change model, the maintenance of the BIM management platform.

Reviewing the Format and Version. There are lots of BIM softwares applied in design and construction in the BIM industry. At the stage of design for PC structure, the architecture, structure and electromechanical models are genrally created by Revit software. The rebar models of standard layer and conversion layer are created by Allplan and Tekla software. The site model is created by Rhino software generally. In addition to the each professional model, it is necessary to integrate the each professional model. The overall model will also be submitted with each professional model.

If the BIM design model will be used into other BIM management platforms for more application, pay more attention to whether the version of the model is applicable. The architecture, structure, and electromechanical model should be saved by the special fomat such as RVT format, Revit 2016 edition. The related family files should be saved by the special fomat such as RFT format, Revit 2016 edition. The rest new software of application can be saved by the IFC format.

Reviewing the model precision. According to the characteristics of PC project, the final model submitted by the desiging institute should meet the requirements of subsequent construction. The fineness of the model is controlled at the specific level such as LOD 400 according to the contract.

Specific accuracy requirements of modeling can refer to the level of cast-in-place structure. For the PC structure, the following key parts must reach the LOD400 level:

1) The joints and the distribution of the steel bars between the prefabricated exterior wall and its underlying cast-in-place components;

2) The flat-fell seam place, the intersections between the prefabricated exterior wall and cast-in-place wall, and other place where the insulation requirements of water and heat are high;

3) The component model in the BIM component library shall include the relevant attribute information of design in addition to the geometric information.

4) The embedded pipelines, the pipeline in the equipment room, the main valve, the slope of the pipeline, the pipeline insulation; various vertical space penetrations such as pipelines/tube wells/lifting holes and other pipeline models mentioned in the contract (the diameter of pipelines greater than 60 $\mathrm{mm})$.

\section{Applications}

Project Overview. The Gucun PC project in Baoshan District, Shanghai, with a total construction area of approximately $177591.74 \mathrm{~m}^{2}$, consists of 15 single buildings of 15 storeys. The project is prefabricated shear wall structure with $40 \%$ prefabrication ratio. There are 16,185 prefabricated components in this project.

Implementation Situation. Using the new review process and the new review criteria of BIM design model for PC project, each model of the PC project can be reviewed accurately one by one. The BIM design models after reviewing are shown in Fig.2. 


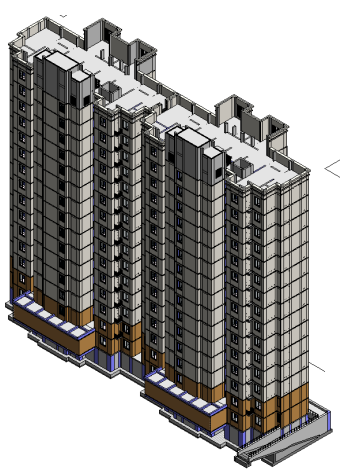

1) The overall model

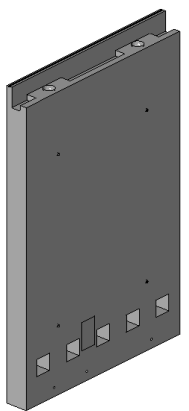

4) The component model

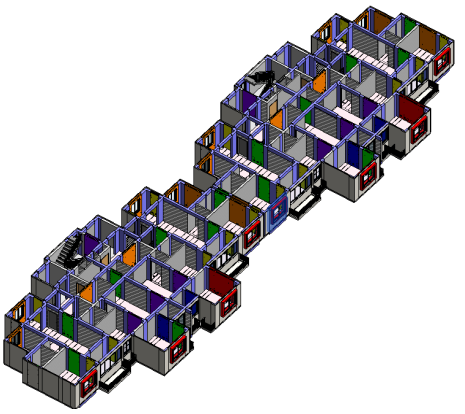

2) The floor model

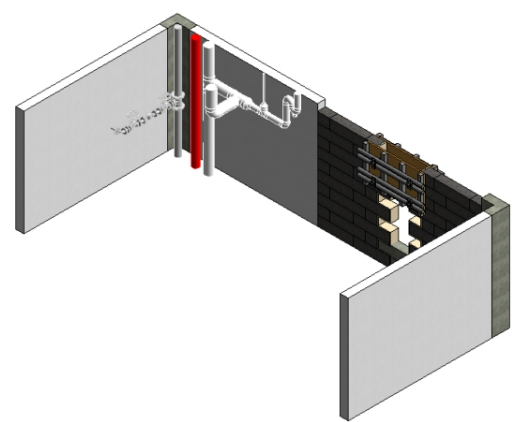

5) The electromechanical model

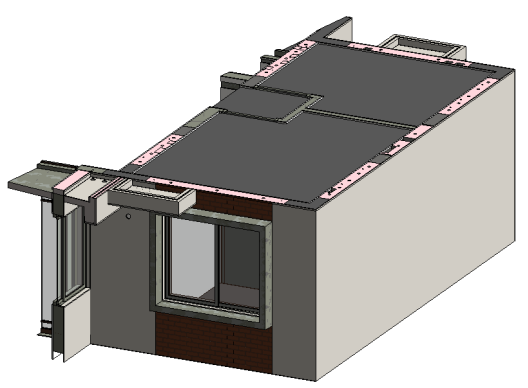

3) The apartment model

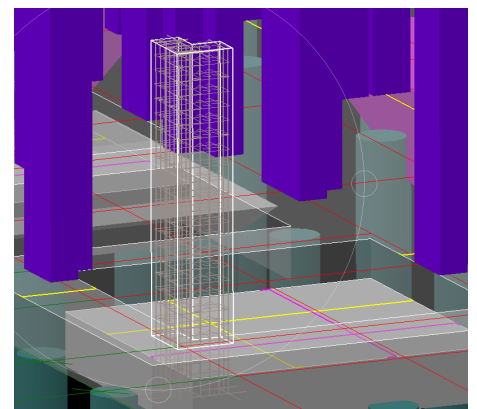

6) The rebar model

Fig. 2 Each model of the PC project after reviewing

\section{Conclusions}

1 ) Compared with the review of the cast-in-place design model, the review content of the PC design model is more extensive, which involves not only the review of the conventional model dimension information, but also the review of various information related to the prefabricated components, such as the prefabricated component itself and the intersection with the cast-in-place parts.

2 ) The model review process proposed in this paper has the characteristic of gradually progressive from the overall to the local. With the model review process, mistakes and omissions of model review reduced significantly.

3 ) The division of design interface, reviewing the format and version, reviewing the model precision are the most important parts in the review criteria of BIM design model for PC structure. Special attention must be paid to the details during the review.

\section{Acknowledgements}

This work was financially supported by the Special Funds of Central Universities Fundamental Research Funds of Tongji University. The authors thank the project team of the Gucun PC project in Shanghai for their hospitability, time and opinions.

\section{References}

[1] L. Ding, Y. Zhou, B. Akinci: Building Information Modeling (BIM) application framework: The process of expanding from 3D to computable nD. Automation in Construction, Vol. 4 (2014), p. 82-93.

[2] J. Jung, S. Hong, S. Jeong: Productive modeling for development of as-built BIM of existing indoor structures. Automation in Construction, Vol. 2 (2014), p. 68-77. 
[3] J. Xie, X.S. Wu: Design and Construction for Prefabricated Shear Wall Structure (China Building Industry Press, Beijing 2017). 